\title{
Simulation on Sawtooth Period Control in Tokamak Plasma*)
}

\author{
Hiroki NATSUME, Takaaki FUJITA, Hideki ARIMOTO and Kozo YAMAZAKI ${ }^{1)}$ \\ Nagoya University, Furo-cho, Chikusa-ku, Nagoya 464-8603, Japan \\ 1)Nagoya University Professor Emeritus
}

(Received 25 November 2014 / Accepted 25 March 2015)

\begin{abstract}
The sawtooth period control is important in inductive operation of tokamak plasma because the sawteeth with long periods trigger the neoclassical tearing modes (NTMs) which reduce the plasma confinement capability significantly. We studied the effect of the sawtooth period control by the electron cyclotron current drive (ECCD) in ITER using the 1.5-dimensional transport code TOTAL. There is the optimum condition (CD direction and radial position) of ECCD for minimizing the sawtooth period. In addition, it was found that the optimum condition hardly depends on the total external heating power from $50 \mathrm{MW}$ to $110 \mathrm{MW}$ and the driven current from 0.5 MA to 1.0 MA. The effect of the sawtooth period control on the critical normalized beta for triggering NTMs was investigated, and it was found that the critical normalized beta increases according to increase in the driven current and ECCD can increase the margin of the normalized beta.
\end{abstract}

(c) 2015 The Japan Society of Plasma Science and Nuclear Fusion Research

Keywords: sawtooth period control, tokamak plasma, neoclassical tearing mode, electron cyclotron current drive, ITER

DOI: $10.1585 /$ pfr.10.3403051

\section{Introduction}

In inductive operation of tokamak plasma such as the standard operation of ITER, the safety factor at the center of plasma becomes below unity through penetration of the plasma current, so that the sawtooth oscillation occurs in the central region of plasma. The sawteeth eject plasma stored energy from the plasma center and limit the fusion power. Furthermore, the sawteeth with long periods may trigger other plasma instabilities such as the neoclassical tearing modes (NTMs) [1,2]. NTMs reduce the plasma confinement capability significantly. Therefore, it is necessary to shorten the sawtooth period so as not to trigger NTMs for achieving a high performance. Using the feature that onset conditions of the sawtooth crashes depend on the magnetic shear at the $q=1$ radius [3], the sawtooth period control is attempted by changing the magnetic shear at the $q=1$ radius using the electron cyclotron current drive (ECCD).

We studied the effect of the sawtooth period control by the electron cyclotron current drive (ECCD) in ITER using the 1.5-dimensional transport code TOTAL (toroidal transport analysis linkage) [4].

\section{Numerical Model}

The heat transport and diffusion of the poloidal magnetic field are solved, while no particle transport was solved (the density profile was assumed to be nearly flat and was fixed). The thermal diffusivity $\chi$ is described as $\chi=\chi^{\mathrm{NC}}+\chi^{\mathrm{AN}}$ where $\chi^{\mathrm{NC}}$ is the neoclassical part and

author'se-mail: natsume-hiroki13@ees.nagoya-u.ac.jp

*) This article is based on the presentation at the 24th International Toki Conference (ITC24).
$\chi^{\mathrm{AN}}$ is the anomalous part. For $\chi^{\mathrm{AN}}$, we used the mixed Bohm/gyro-Bohm model [5].

The Porcelli model $[6,7]$ is used as the triggering sawtooth model. In this model, the sawtooth crashes are triggered when one of the three conditions is satisfied. The condition (1) means that the fast ion stabilization doesn't work within a time scale of mode growth. The condition (2) means that the driving force overcomes the diamagnetic rotation stabilization of thermal ions. The condition (3) means that the resistive internal kink mode is driven for potential energy change close to zero. The full reconnection model is used for the profile after the sawtooth crash. The full reconnection model is a simple model that the magnetic surfaces reconnect within the mixing radius in the Kadomtsev model $[6,8]$.

As a localized current drive model, we adopted ECCD with a Gaussian function $j_{\mathrm{CD}}$ which is given by

$$
j_{\mathrm{CD}}(\rho) \propto \exp \left[-\left\{\left(\rho-\rho_{\mathrm{CD}}\right) / w\right\}^{2}\right],
$$

where $\rho$ is the normalized minor radius, $\rho_{\mathrm{CD}}$ is the normalized radius of position of ECCD and $w$ is the half width for $1 / \mathrm{e}$ of the peak value. The driven current $I_{\mathrm{CD}}$ is given by

$$
I_{\mathrm{CD}}=\int_{S} j_{\mathrm{CD}}(\rho) d S,
$$

where $S$ is the plasma poloidal cross section. ECCD was applied to change the magnetic shear at the $q=1$ radius. We kept $\rho_{\mathrm{CD}}$ constant in time for simple control logic. We adopted $0.2 \times 10^{20} \mathrm{Am}^{-2} \mathrm{~W}^{-1}$ [9] for the driven current efficiency in order to calculate the ECCD power $P_{\mathrm{CD}}$.

The critical $\beta_{\mathrm{N}}$ for triggering NTMs depends on the sawtooth period. The following empirical scaling of 
Table 1 Standard operation parameter of ITER.

\begin{tabular}{cc}
\hline$R[\mathrm{~m}]$ & 6.2 \\
\hline$a[\mathrm{~m}]$ & 2.0 \\
\hline$B_{\mathrm{t}}[\mathrm{T}]$ & 5.3 \\
\hline$I_{\mathrm{p}}[\mathrm{MA}]$ & 15 \\
\hline$\kappa$ & 1.7 \\
\hline$\delta$ & 0.33 \\
\hline $\bar{n}_{\mathrm{e}}\left[\mathrm{m}^{-3}\right]$ & $1.0 \times 10^{20}$ \\
\hline
\end{tabular}

the critical $\beta_{\mathrm{N}}$ for triggering NTMs was derived from a database of plasma parameters with the sawtooth crashes which trigger NTMs and do not [2].

$$
\begin{aligned}
\beta_{\mathrm{N}}^{\mathrm{NTM}}= & 2.614\left(\frac{\tau_{\mathrm{saw}}}{\tau_{\mathrm{r}}}\right)^{-0.4084} \rho_{\theta}^{0.5721}\left(\frac{P_{\mathrm{aux}}}{P_{\mathrm{LH}}}\right)^{0.4204} \\
& \times \bar{n}_{\mathrm{e}}\left[10^{19} \mathrm{~m}^{-3}\right]^{0.4948},
\end{aligned}
$$

where $\beta_{\mathrm{N}}^{\mathrm{NTM}}$ is the critical $\beta_{\mathrm{N}}$ at which the sawtooth crashes will trigger NTMs, $\tau_{\text {saw }}$ is the sawtooth period, $\tau_{\mathrm{r}}$ is the resistive diffusion time at the $q=1$ radius, $\rho_{\theta}$ is the poloidal ion Larmor radius at the $q=1$ radius normalized by the minor radius of the $q=1$ surface, $P_{\text {aux }}$ is the auxiliary heating power, $P_{\mathrm{LH}}$ is the L-H threshold power and $\bar{n}_{\mathrm{e}}$ is the line average electron density.

The external heating except for ECCD is assumed to be simply given by a profile of $\exp \left\{-(\rho / 0.6)^{2}\right\}$ with the power of $P_{\text {ext }}$. The total external heating power $P_{\text {total }}$ is the sum of $P_{\mathrm{CD}}$ and $P_{\text {ext }}$. We used the standard operation parameters of ITER for the plasma parameters, which are shown in Table 1. The edge temperature is set to be $3 \mathrm{keV}$ so that $H H_{y 2} \cong 1$ is obtained with $P_{\text {total }}=73 \mathrm{MW}$, which is the total external heating power in ITER. In this condition, the fusion power $P_{\text {fusion }}$ calculated by TOTAL code is $463 \mathrm{MW}$. In addition, $H H_{y 2} \cong 0.99, \beta_{\mathrm{N}}=2.06$ and $P_{\text {fusion }}=453 \mathrm{MW}$ when $P_{\text {total }}=50 \mathrm{MW}$. In this case, the fusion gain $(Q)$ is about 9.1 which is close to the ITER reference value $\left(Q=10\right.$ for $\left.H H_{y 2}=1\right)$.

\section{Simulation Results}

\subsection{The optimum ECCD direction and posi- tion for the minimum sawtooth period}

In this subsection, we investigate how the sawtooth period normalized by the resistive diffusion time $\tau_{\text {saw }} / \tau_{\mathrm{r}}$ changes when the direction and the radial position of ECCD are changed on the conditions that the total external heating power $P_{\text {total }}$ is $73 \mathrm{MW}, I_{\mathrm{CD}}$ is $0.65 \mathrm{MA}$ and $w$ is 0.06 . The $0.65 \mathrm{MA}$ is obtained assuming that the ECCD efficiency is $0.2 \times 10^{20} \mathrm{Am}^{-2} \mathrm{~W}^{-1}$ and the ECCD power is $20 \mathrm{MW}$ which is the ECCD power in ITER.

Figure 1 shows dependence of $\tau_{\text {saw }} / \tau_{\mathrm{r}}$ on the ECCD position where the ECCD direction is in the same direction as the plasma current (co-ECCD) or counter to it (ctrECCD). The sawtooth crash is triggered by the condition (1) in all cases. In this condition, the sawtooth crash is



Fig. 1 Dependence of $\tau_{\text {saw }} / \tau_{\mathrm{r}}$ on the ECCD position. Circles denote the case with co-ECCD while squares denote the case with counter-ECCD. The $\tau_{\text {saw }} / \tau_{\mathrm{r}}$ without ECCD is shown by the dash line.
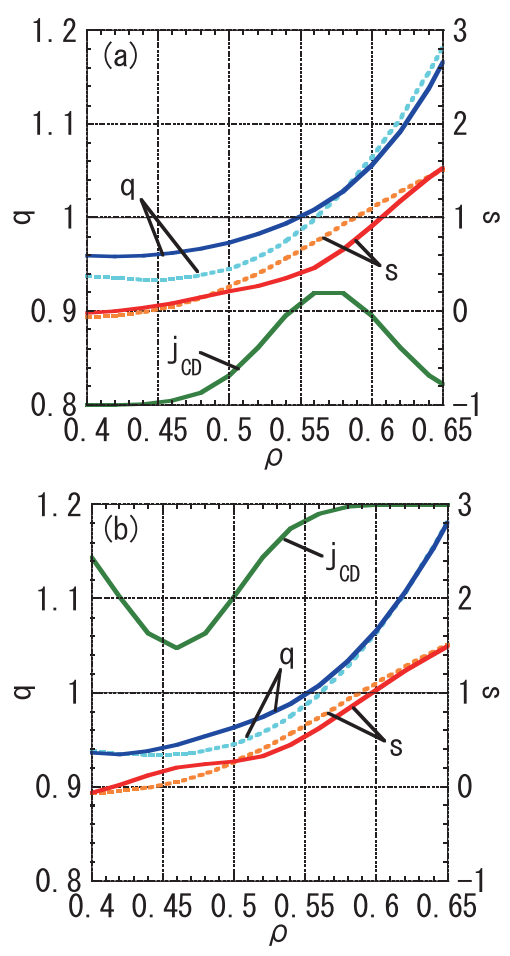

Fig. 2 The profiles of the safety factor, the magnetic shear and the EC-driven current density before a sawtooth crash. The dash lines denote the case without ECCD and the solid lines denote the case with (a) co-ECCD or (b) ctrECCD.

triggered by lowering the magnetic shear at the $q=1$ radius. The minimum $\tau_{\text {saw }} / \tau_{\mathrm{r}}$ is obtained by co-ECCD at $\rho_{\mathrm{CD}}=0.57$. The minimum value is smaller than that without ECCD by about $33 \%$. Figure 2 shows the profiles of the safety factor, the magnetic shear $(s)$ and the driven current density before a sawtooth crash in the case without ECCD and that with co-ECCD at $\rho_{\mathrm{CD}}=0.57$ or ctr-ECCD at $\rho_{\mathrm{CD}}=0.46$. According to Fig. 2 (a), the magnetic shear at the $q=1$ radius is smaller with co-ECCD at $\rho_{\mathrm{CD}}=0.57$, which is located slightly outside the $q=1$ ra- 

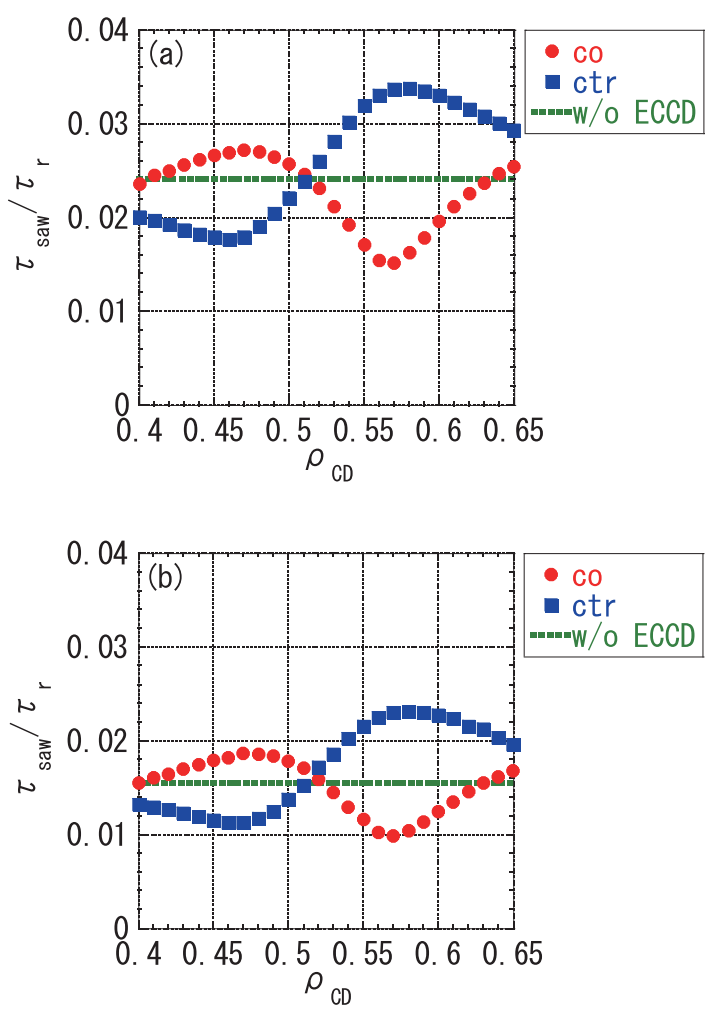

Fig. 3 Dependence of $\tau_{\text {saw }} / \tau_{\mathrm{r}}$ on the ECCD position in cases that (a) $P_{\text {total }}$ is $50 \mathrm{MW}$ and (b) it is $110 \mathrm{MW}$.

dius before the sawtooth crash, than without ECCD. Thus the sawtooth crash is triggered and the sawtooth period becomes short. The ctr-ECCD can also shorten the sawtooth period. This is because ctr-ECCD increases the magnetic shear at the current drive positon and decreases it outside, as shown in Fig. 2 (b). However, decrease in the magnetic shear at the $q=1$ radius by ctr-ECCD is smaller than that by co-ECCD, so co-ECCD is more effective to shorten the sawtooth period.

We also investigate the optimum ECCD direction and position in other total external heating and current drive conditions. Figure 3 shows dependence of $\tau_{\text {saw }} / \tau_{\mathrm{r}}$ on $\rho_{\mathrm{CD}}$ for different $P_{\text {total }}(50 \mathrm{MW}$ and $110 \mathrm{MW})$ with fixed $I_{\mathrm{CD}}$ ( $0.65 \mathrm{MA})$. The $110 \mathrm{MW}$ is the total external heating power expected in ITER after upgrade in the future [10]. According to Fig. 3 , it is found that the $\tau_{\text {saw }} / \tau_{\mathrm{r}}$ is minimized by co-ECCD at $\rho_{\mathrm{CD}}=0.57$, which is the same as the case that $P_{\text {total }}$ is $73 \mathrm{MW}$ and $I_{\mathrm{CD}}$ is $0.65 \mathrm{MA}$, so the optimum ECCD direction and position do not change for $P_{\text {total }}$ between $50 \mathrm{MW}$ and $110 \mathrm{MW}$. Figure 4 shows dependence of $\tau_{\mathrm{saw}} / \tau_{\mathrm{r}}$ on $\rho_{\mathrm{CD}}$ for different $I_{\mathrm{CD}}(0.5 \mathrm{MA}$ and 1.0 MA) with fixed $P_{\text {total }}(73 \mathrm{MW})$. The 1.0 MA of EC-driven current is expected for the ECCD power of $31 \mathrm{MW}$, which is obtained assuming that the ECCD power is about 1.5 times larger than that $20 \mathrm{MW}$ in the future as well as the total external heating power. According to Fig. 4 , the $\tau_{\text {saw }} / \tau_{\mathrm{r}}$ has its minimum at $\rho_{\mathrm{CD}}=0.57$ for $I_{\mathrm{CD}}$ with $0.5 \mathrm{MA}$. On the other hand, the $\tau_{\text {saw }} / \tau_{\mathrm{r}}$ has its minimum at $\rho_{\mathrm{CD}}=0.56$
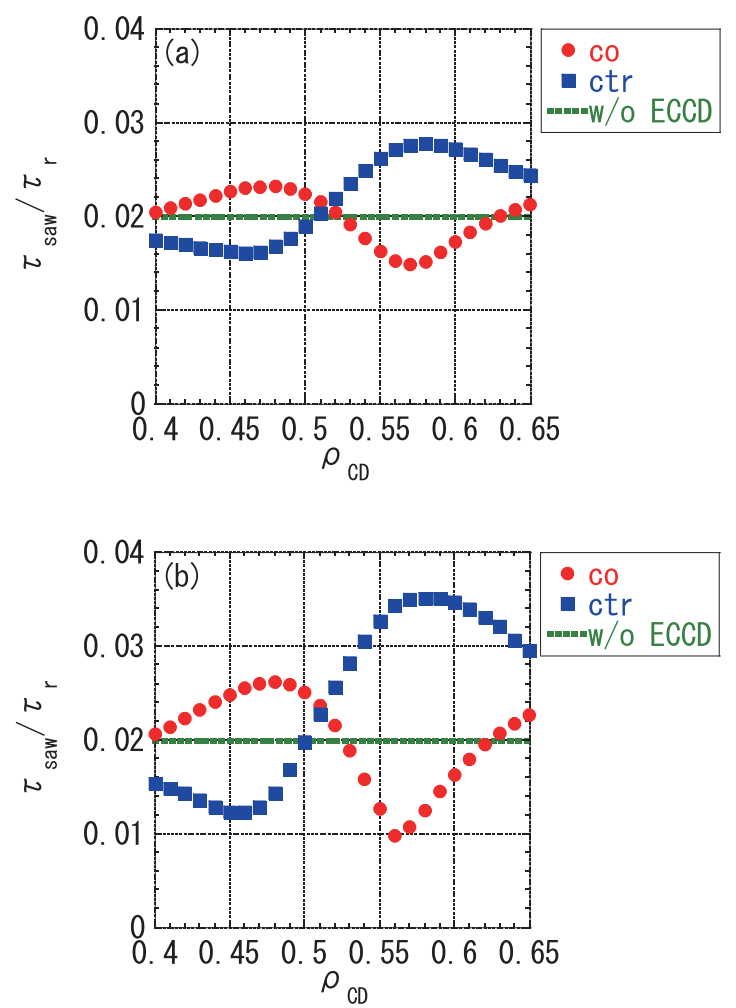

Fig. 4 Dependence of $\tau_{\text {saw }} / \tau_{\mathrm{r}}$ on the ECCD position in cases that (a) $I_{\mathrm{CD}}$ is $0.5 \mathrm{MA}$ and (b) it is $1.0 \mathrm{MA}$.

for $I_{\mathrm{CD}}$ with 1.0 MA, but the difference of $\tau_{\text {saw }} / \tau_{\mathrm{r}}$ between $\rho_{\mathrm{CD}}=0.56$ and $\rho_{\mathrm{CD}}=0.57$ is about $8 \%$, so it can be said that the optimum ECCD direction and position do not change for $I_{\mathrm{CD}}$ within 1.0 MA. Therefore, the optimum ECCD direction and position hardly change within the range of the total external heating power and the driven current expected in ITER.

\subsection{Effect of the sawtooth period control on the onset of NTMs}

In this subsection, we investigate $\beta_{\mathrm{N}}^{\mathrm{NTM}}$ when the sawtooth period is controlled. According to subsection 3.1, we applied co-ECCD with $w=0.06$ on $\rho_{\mathrm{CD}}=0.57$. We considered three cases of $P_{\text {total }}=50,73,110 \mathrm{MW}$, and $I_{\mathrm{CD}}$ is changed in each case.

Figure 5 shows dependence of $\tau_{\text {saw }} / \tau_{\mathrm{r}}$ and $\beta_{\mathrm{N}}^{\mathrm{NTM}}$ on $I_{\mathrm{CD}}$. The higher $I_{\mathrm{CD}}$ is, the larger the effect of ECCD is. Table 2 shows values of $\tau_{\text {saw }} / \tau_{\mathrm{r}}, \beta_{\mathrm{N}}^{\mathrm{NTM}}, \beta_{\mathrm{N}}$ and the margin of $\beta_{\mathrm{N}}\left(\beta_{\mathrm{N}}^{\text {margin }}\right)$, which is defined as $\beta_{\mathrm{N}}^{\text {margin }}=$ $100\left(\beta_{\mathrm{N}}^{\mathrm{NTM}} / \beta_{\mathrm{N}}-1\right)$, in the case without ECCD and the case with ECCD $\left(I_{\mathrm{CD}}\right.$ is $\left.0.65 \mathrm{MA}\right)$ on different total external heating power. According to Table 2, though the possibility that the sawtooth crash triggers NTMs is small even without ECCD, ECCD can shorten $\tau_{\text {saw }} / \tau_{\mathrm{r}}$ by about $33 \sim 37 \%$ and increase $\beta_{\mathrm{N}}^{\mathrm{NTM}}$ by about $19 \sim 22 \%$ for $I_{\mathrm{CD}}$ of $0.65 \mathrm{MA}$. On the other hand, $\beta_{\mathrm{N}}$ hardly change with ECCD, so $\beta_{\mathrm{N}}^{\text {margin }}$ can be increased by about $40 \sim 50 \%$ when the sawtooth period is shortened by ECCD. Therefore, it is 

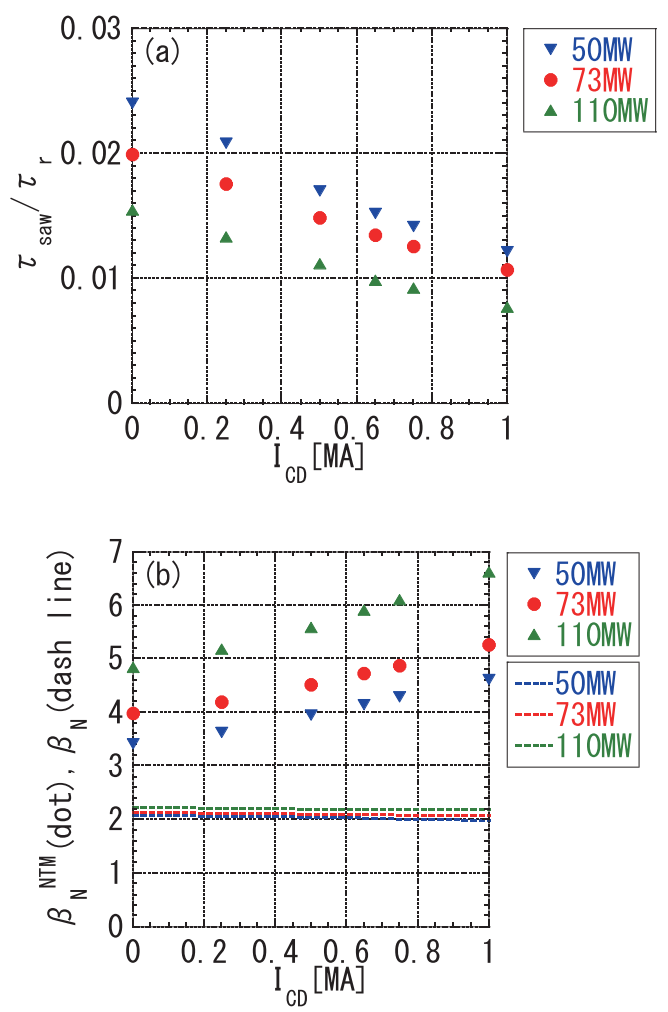

Fig. 5 Dependence of (a) $\tau_{\text {saw }} / \tau_{\mathrm{r}}$ and (b) $\beta_{\mathrm{N}}^{\mathrm{NTM}}$ and $\beta_{\mathrm{N}}$ on $I_{\mathrm{CD}}$. Symbols denote $\tau_{\text {saw }} / \tau_{\mathrm{r}}$ and $\beta_{\mathrm{N}}^{\mathrm{NTM}}$ and dash lines denote $\beta_{\mathrm{N}}$.

Table 2 Values of $\tau_{\text {saw }} / \tau_{\mathrm{r}}, \beta_{\mathrm{N}}^{\mathrm{NTM}}, \beta_{\mathrm{N}}$ and $\beta_{\mathrm{N}}^{\text {margin }}$ for different values of $I_{\mathrm{CD}}\left(\rho_{\mathrm{CD}}=0.57\right)$.

\begin{tabular}{cccccc}
\hline$P_{\text {total }}$ & $I_{\mathrm{CD}}$ & $\tau_{\text {saw }} / \tau_{\mathrm{r}}$ & $\beta_{\mathrm{N}}^{\mathrm{NTM}}$ & $\beta_{\mathrm{N}}$ & $\beta_{\mathrm{N}}^{\text {marg }}$ \\
\hline \multirow{2}{*}{$50 \mathrm{MW}$} & - & 0.0240 & 3.41 & 2.06 & $65 \%$ \\
& $0.65 \mathrm{MA}$ & 0.0152 & 4.15 & 2.02 & $106 \%$ \\
\hline \multirow{2}{*}{$73 \mathrm{MW}$} & - & 0.0199 & 3.97 & 2.13 & $86 \%$ \\
& $0.65 \mathrm{MA}$ & 0.0134 & 4.72 & 2.10 & $125 \%$ \\
\hline \multirow{2}{*}{$110 \mathrm{MW}$} & - & 0.0155 & 4.84 & 2.23 & $117 \%$ \\
& $0.65 \mathrm{MA}$ & 0.0098 & 5.91 & 2.20 & $169 \%$ \\
\hline
\end{tabular}

possible to make the plasma which has the high margin of triggering NTMs by ECCD with the optimum condition.

\section{Summary}

For investigating the effect of the sawtooth period control by ECCD, we evaluated the sawtooth period normalized by the resistive diffusion time and the critical normalized beta for the sawteeth to trigger NTMs on various conditions for standard operation parameters of ITER.

There is the optimum ECCD condition (co-direction to the plasma current and the position slightly outside the $q=1$ surface) and it hardly changes when the total external heating power is changed from $50 \mathrm{MW}$ to $110 \mathrm{MW}$ or the driven current is changed from 0.5 MA to 1.0 MA.

The possibility that the sawtooth crash triggers NTMs is small even without ECCD in ITER. On the other hand, higher ECCD current with the optimum condition makes the sawtooth period shorter and the critical normalized beta higher, so it is possible to make the plasma which has the high margin of triggering NTMs.

According to this study, it is confirmed that ECCD with the optimum condition is effective for the sawtooth period control and preventing the sawteeth from triggering NTMs.

\section{Acknowledgments}

This work was supported by JSPS KAKENHI Grant Number 25420895.

[1] A. Gude et al., Nucl. Fusion 39, 127 (1999).

[2] I.T. Chapman et al., Nucl. Fusion 50, 102001 (2010).

[3] H. Zohm et al., Nucl. Fusion 43, 1570 (2003).

[4] K. Yamazaki and T. Amano, Nucl. Fusion 32, 633 (1992).

[5] M. Erba et al., Plasma Phys. Control. Fusion 39, 261 (1997).

[6] F. Porcelli et al., Plasma Phys. Control. Fusion 38, 2163 (1996).

[7] H. Natsume et al., J. Plasma Fusion Res. 9, 3403048 (2013).

[8] B.B. Kadomtsev, Sov. J. Plasma Phys. 1, 389 (1975).

[9] C. Gormezano et al., Nucl. Fusion 47, S285 (2007).

[10] R. Aymar et al., Plasma Phys. Control. Fusion 44, 519 (2002). 